\title{
Uma proposta de integração do modelo BIM ao sistema last planner
}

\author{
A proposal to integrate the BIM model with the Last \\ Planner system
}

\author{
Priscilla Borges de Freitas Rodrigues \\ Ricardo Luiz Machado \\ Ricardo Mendes Júnior \\ Larsson Diogo Seabra Coelho Romagnoli
}

\section{Resumo}

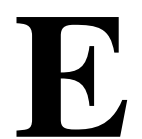

sta pesquisa envolveu-se com a utilização da modelagem da informação da construção (BIM) de maneira integrada à lógica do sistema Last Planner no planejamento e controle da produção em empreendimentos da construção civil. Para isso, a investigação teve como objetivo principal construir um modelo integrador, de forma a atuar na melhoria do planejamento de médio e curto prazos. A abordagem metodológica de pesquisa adotada foi a Design Science Research, que prescreve o projeto e desenvolvimento de artefatos inovadores (neste trabalho, um modelo) destinados a resolver problemas práticos em um banco de dados alimentado por outro software. Dessa maneira, tornou-se possível estabelecer a relação entre cada elemento geométrico do modelo. A construção do modelo de integração passou pelo desenvolvimento de um plug-in para o software Revit, capaz de disponibilizar informações e suas necessidades de materiais, mão de obra e especificações de projeto. A avaliação do modelo foi feita por meio de um estudo empírico em obra de grande porte do setor de edificações. Como principal conclusão verificou-se a sinergia decorrente entre o modelo e o sistema Last Planner, mediante a verificação automática das restrições, do gerenciamento visual e da integração das partes envolvidas com o planejamento de médio e curto prazos, tornando-os mais eficientes.

Palavras-chave: Modelagem da informação da construção. BIM. Last Planner. Planejamento e controle da produção. Revit.

1Priscilla Borges de Freitas

Rodrigues

${ }^{1}$ Pontifícia Universidade Católica de

Goiás

Goiânia - GO - Brasil

${ }^{2}$ Ricardo Luiz Machado

2Pontifícia Universidade Católica de Goiás Goiânia - GO - Brasil

${ }^{3}$ Ricardo Mendes Júnior ${ }^{3}$ Universidade Federal do Paraná Curitiba - PR - Brasil

${ }^{4}$ Larsson Diogo Seabra Coelho

Romagnoli

${ }^{4}$ Pontifícia Universidade Católica de

Goiás

Goiâmia - GO - Brasil

Recebido em 17/05/17 Aceito em 07/11/17

\section{Abstract}

This study investigated the use of building information modelling (BIM) integrated with the logics of the Last Planner system in construction planning and control in building projects. The aim of the study was to build an integrative model in order to improve the planning process in both the medium and short terms. The methodological approach adopted was Design Science Research, which prescribes the design and development of innovative devices (in this study, a model) to solve practical problems. The integration model involved the development of a plug-in for the Revit software, capable of providing information on a database powered by another software. Hence, it was possible to establish the terials, labor, work, and design specifications. The evaluation of the model was made through an empirical study on a large building site. The main conclusion was the resulting synergy between the model and the Last Planner system, through relationship between each geometric element of the project and its needs for maautomatic verification of constraints, visual management, and integration of the parties involved with medium and short-term planning, making them more efficient.

Keywords: Construction Information Modeling. BIM. Production Planning and Control. Revit.

RODRIGUES, P. B. de F.; MACHADO, R. L.; MENDES JÚNIOR, R.; ROMAGNOLI, L. D. S. C. Uma proposta de integração do modelo BIM ao sistema last planner. Ambiente Construído, Porto Alegre, v. 18, n. 4, p. 301-317, out./dez. 2018. ISSN 1678-8621 Associação Nacional de Tecnologia do Ambiente Construído. 


\section{Introdução}

O Sistema Last Planner (LPS) é um modelo de planejamento que almeja melhorar a confiabilidade no fluxo de trabalho, reduzir a variabilidade e as perdas no processo construtivo, além de promover a redução de custos e do tempo de construção (BALLARD, 2000; SACKS; RADOSAVLJEVIC; BARAK, 2010). Esse sistema de planejamento baseia-se em princípios da construção enxuta (lean construction). O LPS consiste em levantar conjuntos de tarefas a serem realizadas e selecionar aquelas que possam efetivamente ser designadas às equipes executoras. Quando as restrições referentes a mão de obra, materiais, especificações de projetos e equipamentos forem removidas, considera-se o plano aprovado.

Para assegurar a constância do fluxo de trabalho, inicialmente é necessário levantar os requisitos necessários para executar as tarefas que o constituem. Machado (2003) sugere a realização do planejamento de antecipações, que consiste em levantar os requisitos necessários para garantir o trabalho eficiente, envolvendo ações destinadas a assegurar que as restrições sejam eliminadas e que elementos que interfiram positivamente no fluxo de trabalho ininterrupto sejam mantidos. A complexidade dessa proposta refere-se à estruturação de um sistema de informações capaz de apoiar as ações gerenciais a serem antecipadas no planejamento da produção (MACHADO, 2003).

As mudanças propostas no processo de planejamento da produção na construção esbarram na qualidade e na quantidade de informações requeridas para a tomada de decisão. Emerge como importante ator nesse cenário a modelagem BIM (Building Information Modelling), ao proporcionar a vantagem de agregar informações em um banco de dados único e se apresentar como uma alternativa destinada ao auxílio do processo de tomada de decisão na gestão de sistemas construtivos. A modelagem BIM permite configurar uma base confiável para apoiar decisões e melhorar os processos do ciclo de vida do projeto, a partir de representações digitais de características físicas e funcionais das edificações (NATIONAL..., 2007).

Segundo Sacks, Radosavljevic e Barak (2010), o pensamento enxuto aplicado à construção tem contribuído para o desenvolvimento de sistemas de planejamento e controle da produção. Para esses autores, a proposta apresentada por Koskela, que conceitua a produção em termos de transformação, fluxo e valor, mostra claramente a repercussão da maturidade da informação sobre os benefícios gerados ao fluxo de trabalho. Nesse contexto, a utilização do LPS aparece como forma de reduzir a variabilidade em processos construtivos e melhorar a coordenação do fluxo de trabalho. Para que isso ocorra, segundo Sacks (2010), é necessário contar com uma tecnologia de suporte capaz de prover a informação necessária à aplicação do sistema de planejamento com uma nova concepção.

Surge como opção tecnológica a modelagem da informação da construção (BIM), que compreende o conjunto de funções necessárias para representar o ciclo de vida de um projeto e, quando adotado corretamente, contribui para um processo de concepção e construção mais integrado, o que gera empreendimentos de maior qualidade, com custos e durações menores (EASTMAN et al., 2011). Segundo esses autores, outros benefícios do uso do BIM podem ser citados, como a melhoria da comunicação, a facilitação do gerenciamento logístico, a possibilidade de analisar comparativamente os planos de execução e o controle do avanço físico da construção.

Ao apresentar a discussão anterior, torna-se importante estabelecer a ligação entre os benefícios proporcionados pelo modelo BIM com as necessidades de informações que surgem na aplicação do LPS. Sacks, Radosavljevic e Barak (2010) analisaram a existência de convergências entre os princípios teóricos da construção enxuta e o BIM e identificaram 56 possíveis interações. Mendes Júnior et al. (2014), após analisarem os resultados obtidos por Sacks, Radosavljevic e Barak (2010), apresentaram um quadro sintético em que identificaram 7 interações associadas diretamente ao planejamento e controle da produção (PCP).

Biotto (2012) apresentou um método para a elaboração do planejamento e controle da obra com a utilização do modelo BIM 4D, em que foram geradas informações utilizadas no processo de tomada de decisão em todos os níveis hierárquicos do planejamento.

Bhatla e Leite (2012) verificaram a interação da construção enxuta e a adoção do BIM em um estudo de caso sobre o processo de planejamento de médio e curto prazo em serviços de instalações elétricas, hidráulicas e mecânicas. Entre os resultados positivos encontrados destacaram-se a funcionalidade de remoção de restrições, a verificação de incompatibilidade entre os projetos, a diminuição do tempo de ciclo e o auxílio na comunicação entre os participantes do projeto na compreensão da produção.

Mendes Júnior et al. (2014) realizaram um estudo de caso utilizando o modelo BIM em atividades de 
PCP. Como resultado da pesquisa foi apresentado um framework teórico de integração de BIM com o LPS, com base na proposta apresentada por Bhatla e Leite (2012). Nessa mesma pesquisa foi constatado ser possível obter mais informações para a produção por meio da utilização de documentos integrados em um único banco de dados. Como resultado da investigação foi observada a redução da variabilidade e a melhora da comunicação entre os envolvidos no projeto, reduzindo o tempo de ciclo e o retrabalho, além de apoiar a integração com os princípios da construção enxuta.

Sacks et al. (2013) desenvolveram e aplicaram um modelo BIM integrado ao LPS, denominado KanBim. Na proposta desses autores foi desenvolvido um modelo em que as equipes de produção podiam verificar on-line as informações sobre o estágio existente em relação à remoção das restrições de cada pacote de trabalho, até que as tarefas que os constituíam estivessem preparadas para serem iniciadas.

Ao analisar os estudos apresentados anteriormente, depara-se com a necessidade de melhorar a integração da modelagem BIM ao LPS no setor da construção, por meio do gerenciamento visual e da verificação automática de restrições na formação do PCP. É nesse contexto que este trabalho inserese, com o objetivo geral de operacionalizar a integração do modelo BIM ao LPS, com os planos de médio e curto prazos, gerenciados visualmente no modelo 3D. Diante desse objetivo apareceram como objetivos secundários:

(a) desenvolver um plug-in para o software Revit destinado à verificação automática de restrições e elaboração de planos de médio e curto prazos;

(b) desenvolver um software desktop para inserção de dados da obra para permitir a verificação automática de restrições pelo plug-in; e

(c) implantar o modelo em um estudo empírico para avaliar sua utilidade e aplicabilidade.

\section{Revisão bibliográfica}

\section{Sistema Last Planner (LPS)}

O LPSfoi proposto por Ballard e Howell em meados dos anos 90 e pode ser considerado a principal aplicação da filosofia da manufatura enxuta na indústria da construção civil. Esse sistema de planejamento e controle da construção enfatiza a necessidade de gerenciar os fluxos de produção e o comprometimento das equipes de trabalho (BALLARD, 2000). Ainda segundo o mesmo autor, o LPS propicia uma produção mais confiável, ao promover a redução da variabilidade do fluxo de trabalho.

Seguindo a hierarquização do processo de planejamento em horizontes de tempo distintos proposta por Laufer e Tucker (1987), o LPS apresenta três níveis: a elaboração do planejamento de longo prazo, a construção do planejamento de médio prazo (o lookahead) e o planejamento de curto prazo (o weekly planning ou planejamento de comprometimento).

O planejamento de longo prazo, também chamado de plano mestre, deve estabelecer objetivos globais que norteiam o empreendimento como um todo e definir a sequência, duração e o ritmo das macroetapas do empreendimento (BALLARD, 2000). Segundo Ballard (1997), o plano mestre serve a vários propósitos, como a projeção de gastos e o desembolso.

Já o planejamento lookahead possui como função de maior destaque o controle do fluxo de trabalho, por meio da identificação e remoção sistemática das restrições (BALLARD, 1997). De acordo com Ballard e Howell (1998), é nesse nível do processo de planejamento que o plano mestre é detalhado e ajustado de acordo com as informações sobre o empreendimento que se tornam disponíveis no horizonte de médio prazo. Para Bernardes (2001), a principal função desse planejamento é a ligação entre o planejamento de longo prazo e o planejamento de curto prazo.

O planejamento lookahead serve como um mecanismo de proteção da produção no horizonte de curto prazo, tornando-o mais eficiente, uma vez que libera para a execução apenas as atividades cujas restrições foram removidas (BALLARD, 2000). O terceiro nível do LPS compreende o planejamento de comprometimento, que tem como objetivo conciliar o que deve ser feito com o que pode ser feito e decidir a respeito do que será efetivamente realizado, em relação aos pacotes de trabalho e aos responsáveis por executá-los, com base nos recursos disponíveis e no cumprimento de pré-requisitos (BALLARD; HOWELL, 1998).

Segundo Ballard (2000) é no nível do planejamento de curto prazo que ocorre a programação semanal do trabalho, por meio da orientação das atribuições das equipes responsáveis por executar cada pacote de trabalho, após a remoção de todas as restrições no planejamento lookahead.

Ao analisar a proposta do LPS, constata-se que sua essência é baseada no gerenciamento de informações a respeito das restrições, que devem ser removidas a fim de gerar um fluxo de trabalho confiável e sem interrupções. A modelagem de 
informações pela proposta do BIM aparece como importante oportunidade de alavancagem do potencial de aplicação do sistema Last Plannerno cenário discutido anteriormente.

\section{Building Information Modeling (BIM)}

Segundo Eastman et al. (2011), o BIM é uma proposta de modelagem associada aos processos de produzir, comunicar e analisar o projeto de uma edificação. Succar (2009) apresenta o BIM como um conjunto de políticas, processos e tecnologias que geram uma metodologia para gerenciar projetos da edificação, a partir de dados em formato digital, em todo o ciclo de vida da edificação.

A principal diferença entre um software de modelagem 3D e um software BIM é a capacidade de gerar objetos paramétricos. A parametricidade permite gerar objetos editáveis, que podem ser alterados automaticamente e suportar a plataforma BIM. Sem essa capacidade, o software é apenas um modelador tridimensional. Eastman et al (2008) classificam os usos e benefícios do BIM considerando as fases do ciclo de vida do projeto, da seguinte forma:

(a) concepção do projeto, envolvendo o estudo preliminar e sua viabilidade; projeto, englobando visualização, correções dos elementos no modelo, geração de desenhos 2D, trabalho multidisciplinar, extração automática de quantitativos, melhorias no processo de análise energética e de sustentabilidade;

(b) execução, incluindo a sincronização do planejamento da obra com os objetos do modelo, descoberta de interferências entre os elementos do edifício, implementação da construção enxuta, sincronização das fases de aquisição, projeto e construção; e

(c) operação, promovendo a melhoria no gerenciamento da operação dos sistemas da edificação.

Os modelos BIM podem ser caracterizados pelo seu âmbito dimensional, referenciados por $\mathrm{nD}$, em que $\mathrm{n}$ indica a dimensão do modelo. Segundo Rodas (2015), o modelo mais explorado de BIM é o 3D.

Ainda segundo Rodas (2015), a dimensão conhecida como BIM 4D refere-se ao tempo, que é capaz de oferecer um planejamento temporal, possibilitando acompanhar a edificação ao longo de seu ciclo de vida. Nessa dimensão pode-se visualizar e avaliar o progresso das atividades a serem executadas durante a construção da edificação.

O BIM 5D é associado às estimativas de custos, designando ao modelo a capacidade de atribuir valores aos elementos do projeto. Nessa dimensão, o modelo BIM passa a ser um instrumento de auxílio à orçamentação e extração de quantitativos, refletindo automaticamente nos custos do empreendimento qualquer alteração no projeto.

Os modelos BIM 6D e 7D envolvem aspectos relativos à sustentabilidade, gestão e manutenção preventiva do empreendimento. Segundo Rodas (2015), existe a tendência de caracterizar o modelo BIM 6D com foco voltado à sustentabilidade do empreendimento e o 7D para a gestão e manutenção de edifícios.

\section{Metodologia de pesquisa}

Para atingir seus objetivos, a pesquisa adotou a abordagem metodológica da Design Science, que estabelece um processo sistemático, que tem como objetivo projetar e desenvolver artefatos inovadores com condições de resolver problemas, mostrando-se relevante também para o campo prático (VAN AKEN, 2004; MARCH; STOREY, 2008; DRESCH; LACERDA;MIGUEL, 2015). Essa abordagem foi selecionada entre as opções existentes em função de sua aderência ao problema da pesquisa, que demandava a criação de um modelo prático destinado a aperfeiçoar a integração entre o projeto e o planejamento de médio e curto prazo na obra.

A pesquisa foi realizada em quatro fases, conforme apresentado no Quadro 1.

A revisão da literatura procurou assegurar a adoção de um problema com relevância para o planejamento e controle da produção dentro da indústria da arquitetura, engenharia e construção.

A fase 2, do estudo exploratório, foi iniciada com a análise e avaliação das alternativas para modelagem BIM. Após a avaliação, adotou-se o software Revit para aplicação na pesquisa e capacitação dos pesquisadores. Em seguida, foram analisadas organizações na localidade da pesquisa, a fim de identificar construtoras envolvidas com a implantação do BIM e acessíveis às intervenções almejadas pela pesquisa. Ao término dessa avaliação, foi adotada uma organização que estava realizando um processo inicial de implantação do BIM, mas que praticava um processo de PCP tradicional. 
Quadro 1 - Delineamento da pesquisa

\begin{tabular}{|c|c|c|}
\hline Fase & Descrição & $\begin{array}{cc}\text { Atividades Realizadas } \\
\end{array}$ \\
\hline 1 & $\begin{array}{l}\text { Revisão da } \\
\text { Literatura }\end{array}$ & Identificação e delimitação do problema de pesquisa \\
\hline 2 & $\begin{array}{l}\text { Estudo } \\
\text { exploratório }\end{array}$ & $\begin{array}{l}\text { Busca de conhecimento no software } \text { REVIT }^{\odot} \text {, banco de dados e software } \\
\text { destinado a realização do sistema LastPLanner }{ }^{\odot} \text {; Escolha da organização } \\
\text { adotada como objeto de estudo; Compreensão do processo PCP e do estado } \\
\text { de implantação da modelagem BIM na organização adotada para estudo. }\end{array}$ \\
\hline 3 & $\begin{array}{l}\text { Desenvolvimento } \\
\text { do modelo BIM }\end{array}$ & $\begin{array}{l}\text { Escolha da obra; Elaboração do modelo preliminar; Aplicação do modelo; } \\
\text { Avaliação do modelo. }\end{array}$ \\
\hline 4 & $\begin{array}{l}\text { Consolidação do } \\
\text { modelo BIM }\end{array}$ & $\begin{array}{l}\text { Comunicação sobre os resultados alcançados; Avaliação da contribuição } \\
\text { teórico/prática do trabalho. }\end{array}$ \\
\hline
\end{tabular}

A fase 3, de desenvolvimento do modelo, envolveu um estudo empírico em uma obra da construtora escolhida.

O estudo empírico foi realizado em três etapas, que visaram compreender o problema estudado, desenvolver e testar o modelo proposto e identificar a contribuição prática e teórica da solução obtida, conforme apresentado no Quadro 2 .

O objeto de estudo selecionado para atingir os objetivos da pesquisa foi uma obra de uma construtora localizada em Goiânia, GO. A obra estudada, ilustrada na Figura 1, foi escolhida devido ao processo de implantação da gestão e do planejamento, com a utilização do BIM.

A obra envolvia um projeto de um shopping center com uma área construída de $52.134,09 \mathrm{~m}^{2}$, e valor estimado de R\$ 104.500.000,00. O empreendimento foi iniciado em novembro de 2014 e concluído em abril de 2017.

$\mathrm{Na}$ fase 4 o modelo gerado foi avaliado com base nos constructos apresentados no Quadro 3. Para cada subconstructo foi gerada uma questão aplicada na entrevista. O processo de avaliação ocorreu por meio da formação de um grupo focal, constituído pelo engenheiro de planejamento, pela arquiteta coordenadora dos projetos da obra e pelo engenheiro responsável pela produção, além de estagiários usuários do modelo.

Inicialmente foram comunicados aos entrevistados os resultados alcançados pelo projeto $\mathrm{e}$ as peculiaridades do modelo gerado. Após essa fase introdutória, foi solicitado aos participantes do grupo focal para que avaliassem os resultados do projeto. Ao término das entrevistas, a equipe de pesquisadores analisou a contribuição teórica e prática produzida pela pesquisa.

\section{Desenvolvimento do modelo de integração entre o BIM e o sistema last planner}

\section{Introdução}

A comunicação entre o modelo 3D e o LPSfoi estruturada conforme a Figura 2. A ligação dos dados entre os elementos do modelo de integração foi realizada por meio da identificação de códigos de identidades nas estruturas geométricas do modelo 3D no Revit. Como se percebe na Figura 2, um banco de dados serviu de elemento intermediário para estabelecer a comunicação entre o software de modelagem Revit e o software de planejamento L7.

O software Revit na versão 2017 foi adotado no modelo. O software plug-in foi desenvolvido na linguagem de programação C\# e o ambiente IDE Visual studio foi utilizado na sua construção. O banco de dados foi estruturado no ambiente Firebird 3.0 e o IBExpert foi utilizado para seu gerenciamento. O software de planejamento L7 foi construído na plataforma IDE Lazarus e codificado na linguagem de programação DELPHI. O trabalho de Rodrigues (2017) apresenta mais detalhes sobre a configuração da estrutura apresentada na Figura 2.

\section{Desenvolvimento de um plug-in destinado à elaboração dos planos lookahead e Work Week Plan (WWP)}

Para fazer o planejamento da obra nos horizontes de médio e curto prazos, foi desenvolvido um plug-in, conforme apresentado no Quadro 4. O plug-in ainda recebeu funcionalidades que proporcionaram a visualização do que foi executado na obra, para permitir o acompanhamento de seu progresso. 
Quadro 2 - Etapas do estudo empírico

\begin{tabular}{|l|l|l|}
\hline \multicolumn{1}{|c|}{$\begin{array}{c}\text { EnAPA 1 } \\
\text { gerencial da empresa }\end{array}$} & \multicolumn{1}{|c|}{$\begin{array}{c}\text { ETAPA 2 } \\
\text { Operacionalização do modelo }\end{array}$} & \multicolumn{1}{c|}{$\begin{array}{c}\text { ETAPA 3 } \\
\text { Avaliação do modelo }\end{array}$} \\
\hline $\begin{array}{l}\text { Reunião preliminar com os } \\
\text { gestores da empresa }\end{array}$ & Adequação do plug-in & Aplicação do modelo \\
\hline $\begin{array}{l}\text { Acompanhamento de reuniões } \\
\text { de planejamento }\end{array}$ & Adequação do software L7 & $\begin{array}{l}\text { Avaliação e melhoramento do } \\
\text { modelo }\end{array}$ \\
\hline $\begin{array}{l}\text { Desenvolvimento de um } \\
\text { diagrama de fluxo de dados }\end{array}$ & Realização de testes no modelo & $\begin{array}{l}\text { Apresentação do modelo } \\
\text { proposto aos gestores da obra }\end{array}$ \\
\hline $\begin{array}{l}\text { Proposta de um modelo } \\
\text { preliminar }\end{array}$ & Refinamento do modelo & \\
\hline
\end{tabular}

Figura 1 - A obra estudada

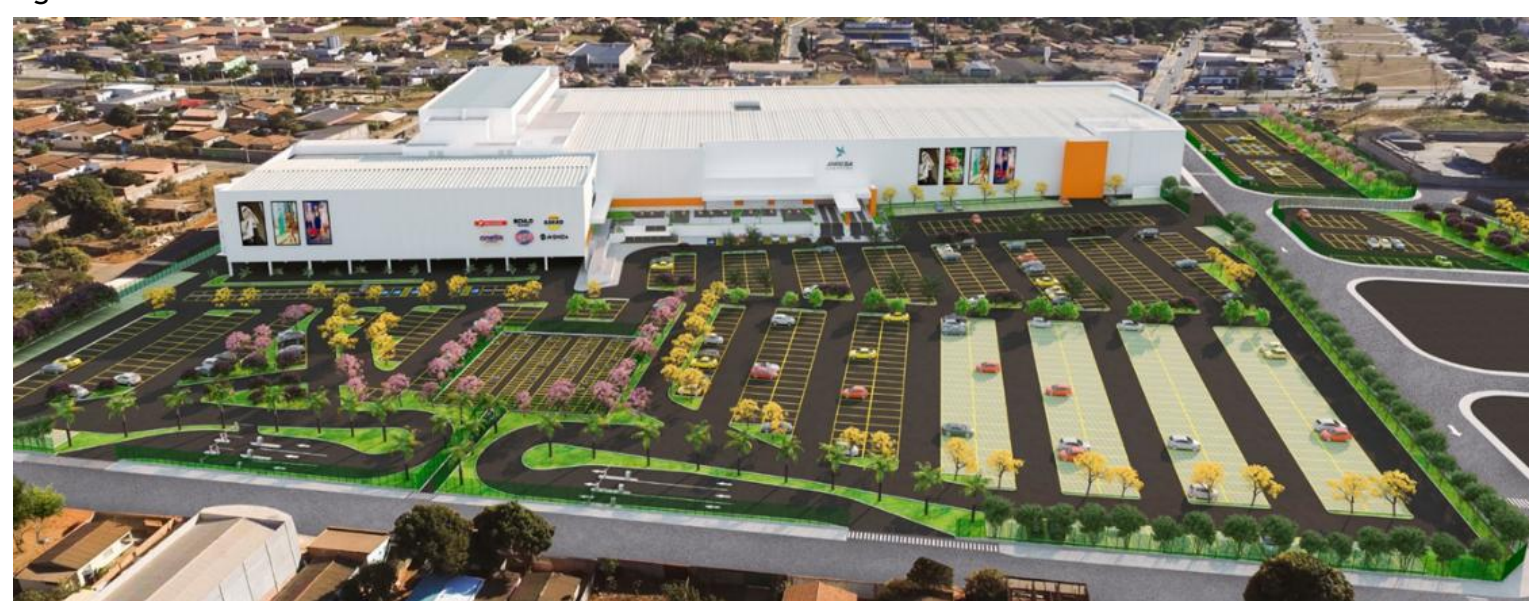

Fonte: fornecida pela obra estudada (2017).

Quadro 3 - Questões para avaliação dos constructos

\begin{tabular}{|c|c|c|}
\hline & Constructo: Utilidade & Questões \\
\hline \multirow{4}{*}{ 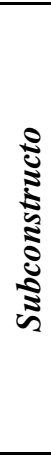 } & Confiabilidade da informação & $\begin{array}{l}\text { A informação gerada pelo modelo é fidedigna a } \\
\text { realidade? Pode ser visualizada em tempo hábil para } \\
\text { sua utilização? }\end{array}$ \\
\hline & Aumento da comunicação & $\begin{array}{l}\text { A informação gerada pelo modelo aumenta a } \\
\text { comunicação entre as partes interessadas? }\end{array}$ \\
\hline & Utilização das informações geradas & $\begin{array}{l}\text { As informações oferecidas pelo modelo são utilizadas } \\
\text { na construção do planejamento e controle da produção, } \\
\text { tornando-o eficaz? }\end{array}$ \\
\hline & Integração das informações geradas & $\begin{array}{l}\text { As informações que ficavam disponíveis em banco de } \\
\text { dados diferentes com o modelo passaram a está } \\
\text { disponível em um único banco de dados? }\end{array}$ \\
\hline \multirow{5}{*}{ 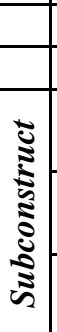 } & Constructo: Funcionalidade & $\begin{array}{l}\text { Questões } \\
\end{array}$ \\
\hline & Facilidade de uso & O aprendizado na operação do modelo é fácil? \\
\hline & Facilidade de entender as informações & $\begin{array}{l}\text { É de fácil entendimento as informações geradas e sua } \\
\text { utilização? }\end{array}$ \\
\hline & Retroalimentação eficaz & $\begin{array}{l}\text { A alimentação do modelo com informações de campo } \\
\text { é feita de maneira fácil? }\end{array}$ \\
\hline & Interesse em continuar o uso da ferramenta & $\begin{array}{l}\text { Há interesse da empresa em continuar com o uso do } \\
\text { modelo desenvolvido? }\end{array}$ \\
\hline
\end{tabular}

306 Rodrigues, P. B. de F.; Machado, R. L.; Mendes Júnior, R.; Romagnoli, L. D. S. C. 
Figura 2 - Comunicação dos dados

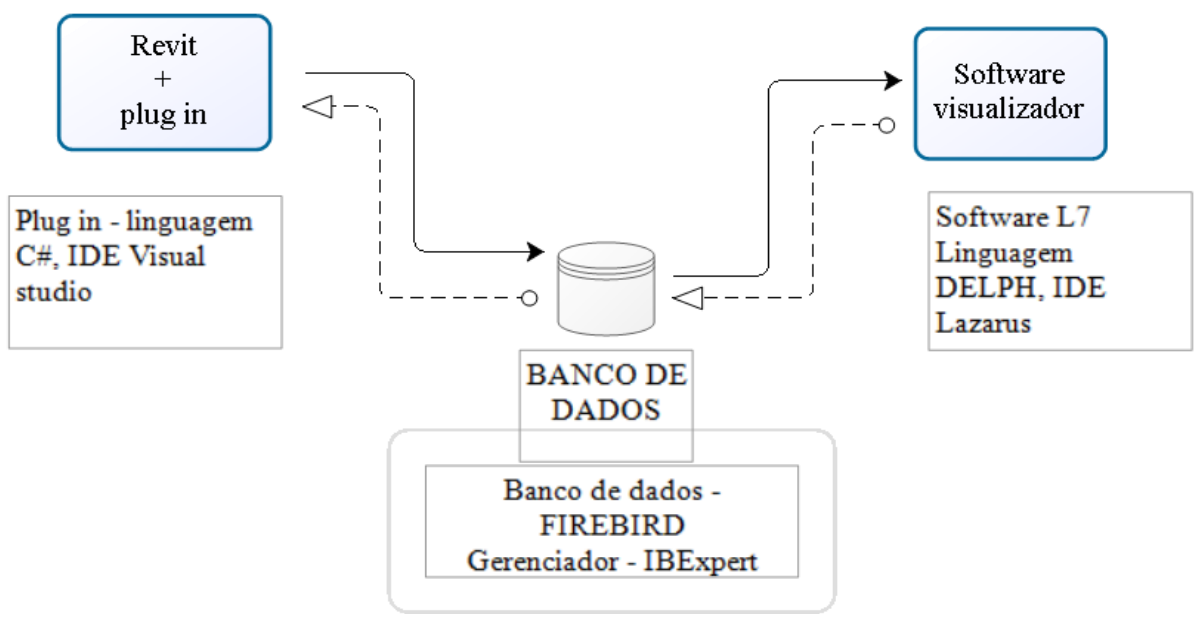

Quadro 4 - Funcionalidades, parâmetros e objetivos do modelo integrado

\begin{tabular}{|l|l|l|}
\hline \multicolumn{1}{|c|}{ Funcionalidades } & \multicolumn{1}{|c|}{ Parâmetros } & \multicolumn{1}{c|}{ Objetivos } \\
\hline \multirow{3}{*}{$\begin{array}{l}\text { Ligação da obra ao } \\
\text { modelo 3D }\end{array}$} & Toc serviço & $\begin{array}{l}\text { Atribuir o elemento geométrico a estrutura da } \\
\text { obra criada }\end{array}$ \\
\cline { 2 - 3 } & Toc grupo & $\begin{array}{l}\text { Atribuir o elemento geométrico a estrutura da } \\
\text { obra criada }\end{array}$ \\
\hline \multirow{4}{*}{ Lookahead } & L7pesoprodutividade & Atribuir consumo de mão de obra \\
\cline { 2 - 3 } & L7insumovinculado & Atribuir insumo necessário à execução \\
\cline { 2 - 3 } & L7consumoinsumovinculado & Atribuir o consumo do insumo \\
\cline { 2 - 3 } & L7descrestrição & Atribuir restrição de projeto \\
\hline Workweekplan & WWP & Atribuir data de comprometimento \\
\hline Avanço físico & Percentual executado & $\begin{array}{l}\text { Atribuir conclusão do serviço, mesmo que } \\
\text { parcial. }\end{array}$ \\
\hline
\end{tabular}

Dentre as funcionalidades desenvolvidas no plugin, a mais relevante para esta pesquisa foi a relacionada ao planejamento lookahead. Essa funcionalidade foi criada com o objetivo de selecionar o trecho do projeto que se pretendia realizar num horizonte de quatro a seis semanas e verificar suas restrições referentes aos insumos de mão de obra, materiais e especificações de projetos.

Para que a funcionalidade lookahead fosse implantada, houve a necessidade da criação de alguns parâmetros no modelo do Revit. Inicialmente, para a verificação da restrição referente à mão de obra, foi criado um parâmetro de projeto, do tipo numérico, intitulado L7PesoProdutividade, que possibilitava atribuir pesos diferentes em relação aos trechos que envolviam níveis diferentes de consumo de mão de obra referente ao mesmo serviço.

Para a verificação da restrição referente aos materiais necessários à execução do serviço programado foram criados dois parâmetros de projeto: um do tipo numérico, intitulado
L7ConsumoInsumoVinculado, e outro do tipo texto, denominado L7InsumoVinculado.

O parâmetro L7InsumoVinculado foi criado com a finalidade de vincular o elemento geométrico pertencente a um serviço ao nome da peça necessária para a execução do serviço. O parâmetro L7ConsumoInsumoVinculado foi criado para associar ao elemento geométrico o consumo do material referente ao serviço ao qual está vinculado.

Para a verificação da restrição ligada às especificações de projeto houve a necessidade de criação de um parâmetro, do tipo texto, denominado L7DescRestricao, cuja função era a de registrar a pendência relacionada a um determinado trecho do projeto, caso fosse selecionado para inclusão na programação lookahead. Esse parâmetro visava registrar alguma mudança no projeto de determinado elemento construtivo. Na Figura 3 é apresentado um exemplo, em que o trecho que recebeu a cor roxa representa uma alteração do projeto de locação da casa de bombas, como registrado no parâmetro L7DescRestricao. 
Com a criação dos parâmetros referentes às informações de projetos e aos insumos necessários aos serviços foi possível selecionar um trecho no modelo 3D, atribuir um período de execução, verificar os insumos disponíveis na obra e analisar a existência de restrições.

Quando se realizava a verificação através do plugin era ativado um procedimento que fazia com que o trecho selecionado para ser incluído no lookahead apresentasse a cor verde, caso as necessidades de mão de obra, materiais e projeto fossem atendidas. Quando o trecho selecionado não possuía suas necessidades atendidas em relação a algum tipo de restrição, era apresentado na cor vermelha, conforme as Figuras 4 e 5.

Outra funcionalidade inserida no plug-in foi a relacionada ao plano de curto prazo, intitulado WWP, que mostrava, de forma visual, depois da remoção das restrições e comprometimento da equipe, quais eram os serviços a serem realizados na semana vindoura. Para isso, bastava selecionar o trecho e lhe atribuir uma data para sua execução, que recebia a cor verde em um tom mais escuro que a cor atribuída ao do lookahead, conforme indicado pela seta apresentada na Figura 6.

O plug-in permitia ainda que fosse selecionado no modelo 3D um trecho que já havia sido executado na obra e lhe atribuir a data da execução. No modelo 3D, o trecho executado mudava da cor laranja para azul, conforme ilustrado na Figura 7.

\section{Desenvolvimento do software de planejamento L7}

Para o acompanhamento da obra e inserção dos dados relativos aos materiais e mão de obra disponíveis que alimentavam o banco de dados foi desenvolvido o software desktop L7.

Figura 3 - Visualização de um trecho com restrição do tipo projeto

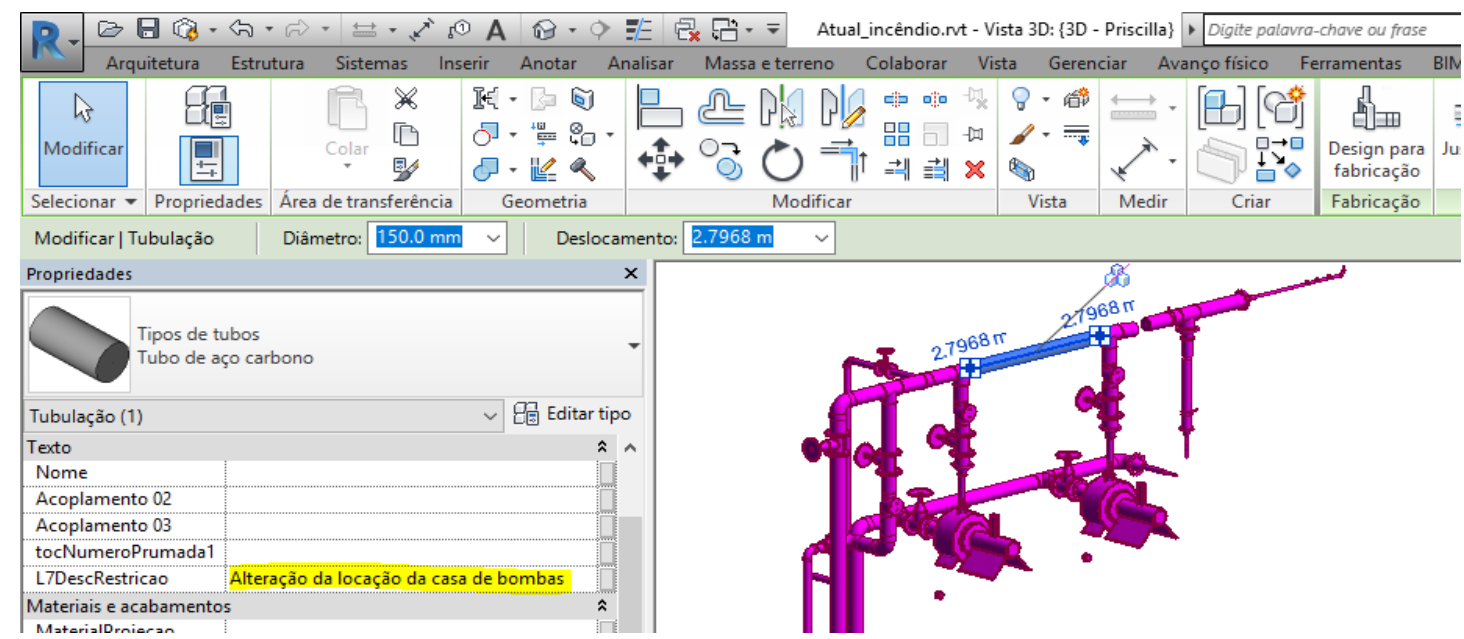

Figura 4 - Visualização de um trecho sem restrição no lookahead

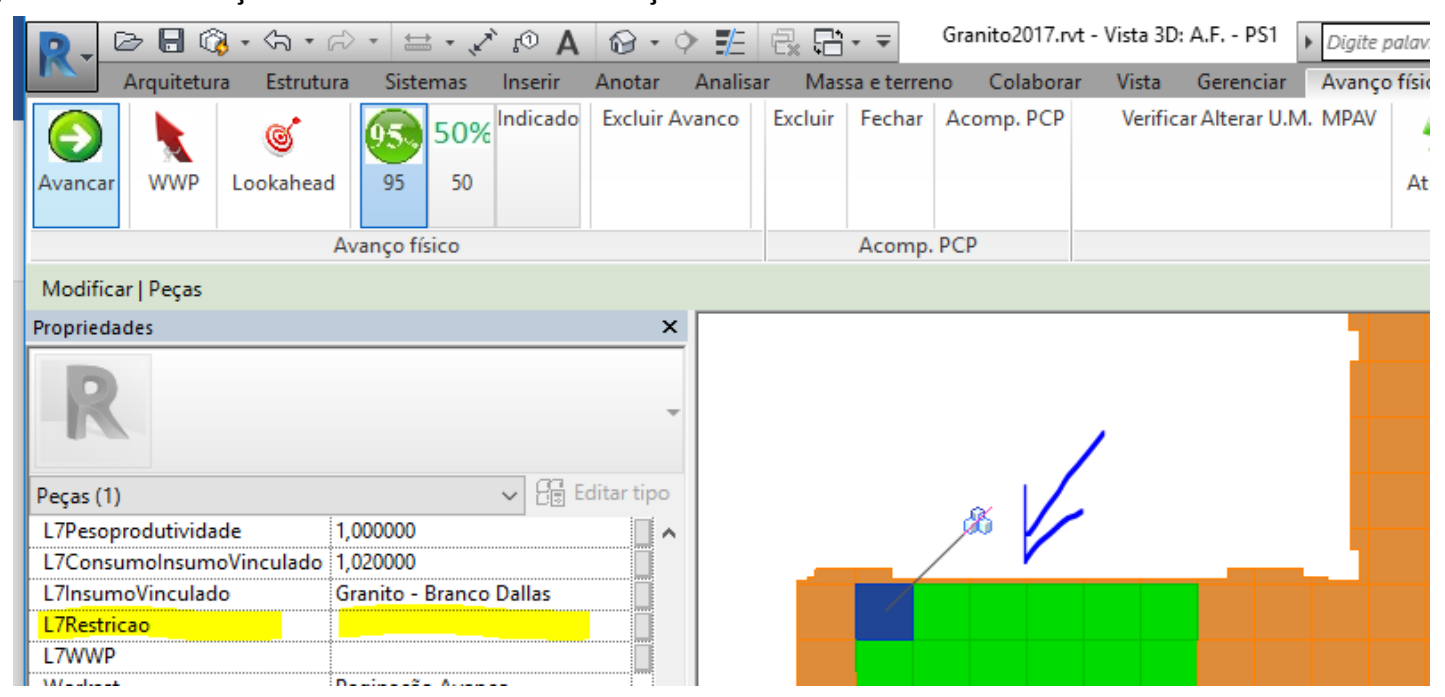

308 Rodrigues, P. B. de F.; Machado, R. L.; Mendes Júnior, R.; Romagnoli, L. D. S. C. 
Figura 5 - Visualização de um trecho com restrição no lookahead

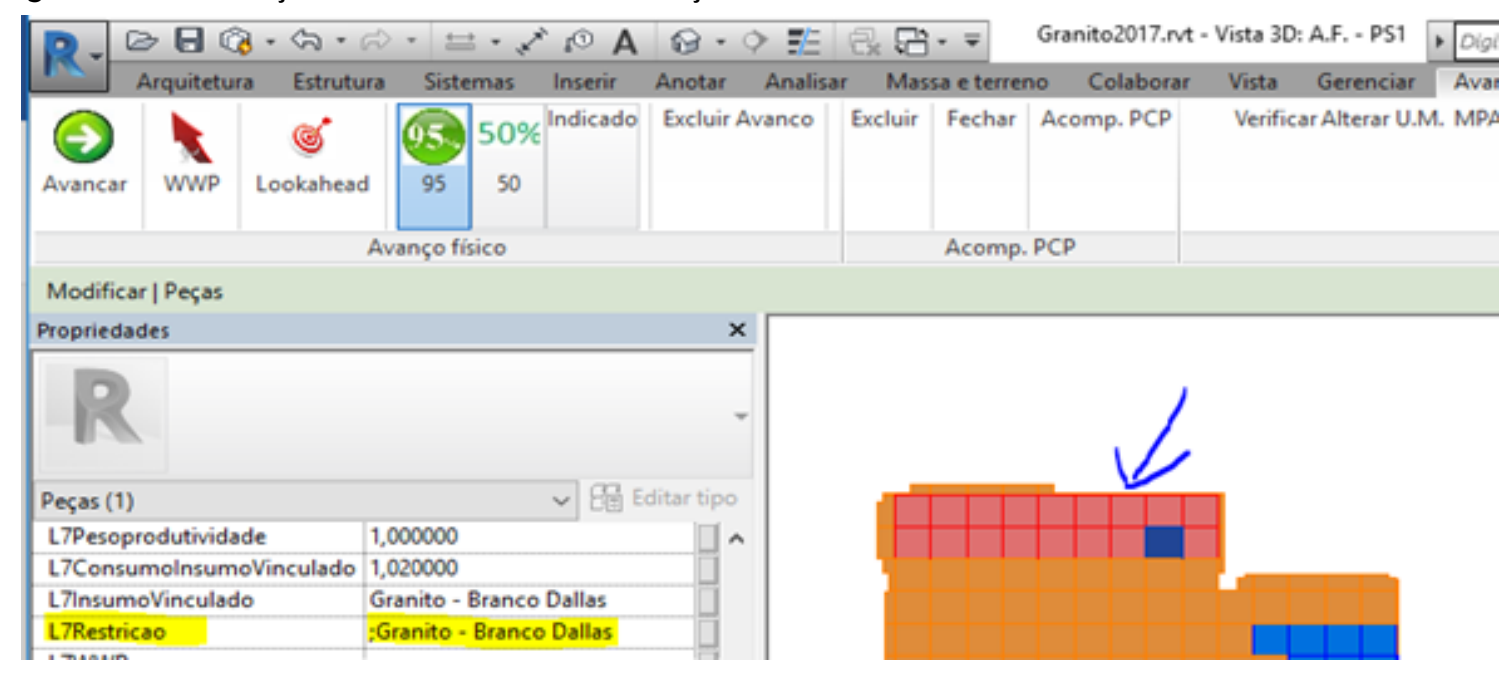

Figura 6 - Visualização de um trecho inserido no WWP

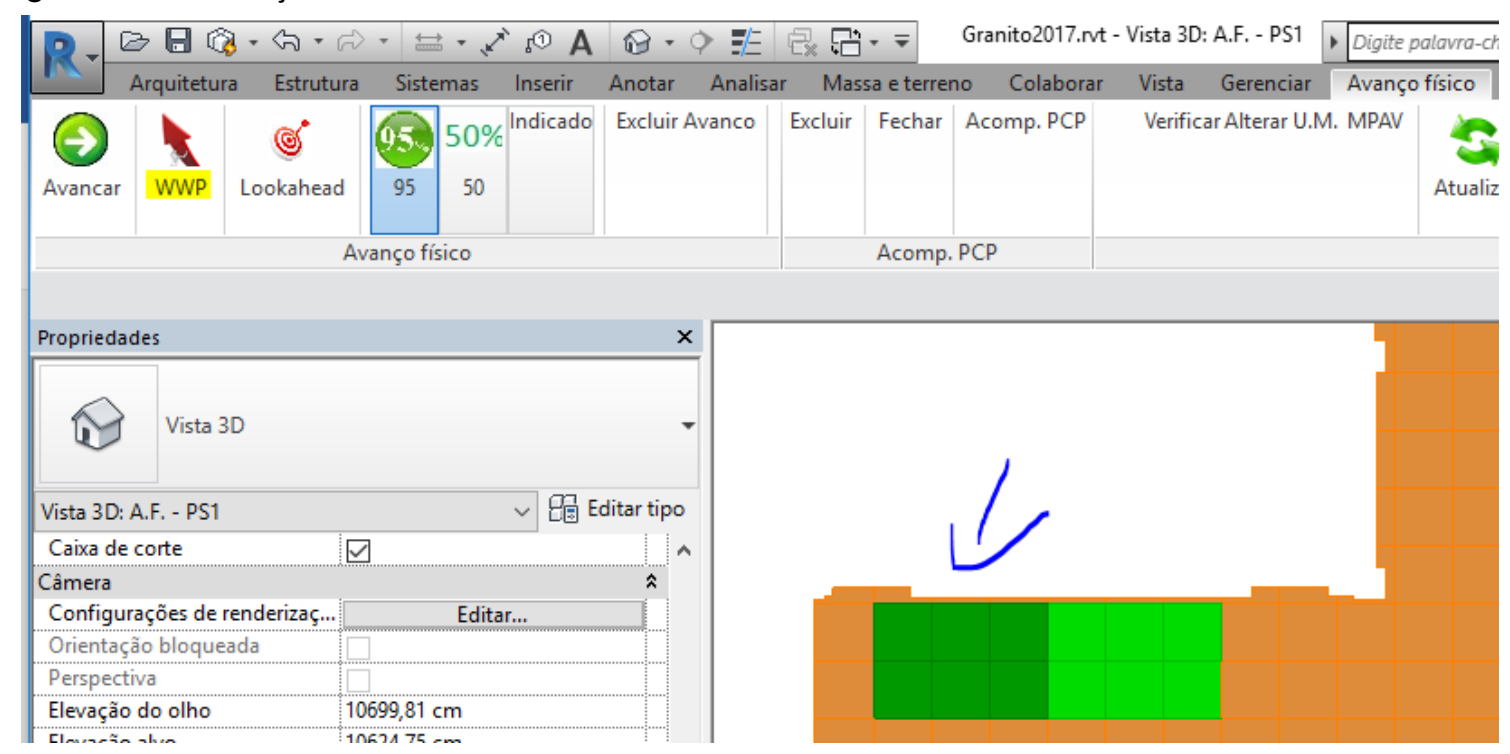

\section{Figura 7 - Visualização de um trecho executado}

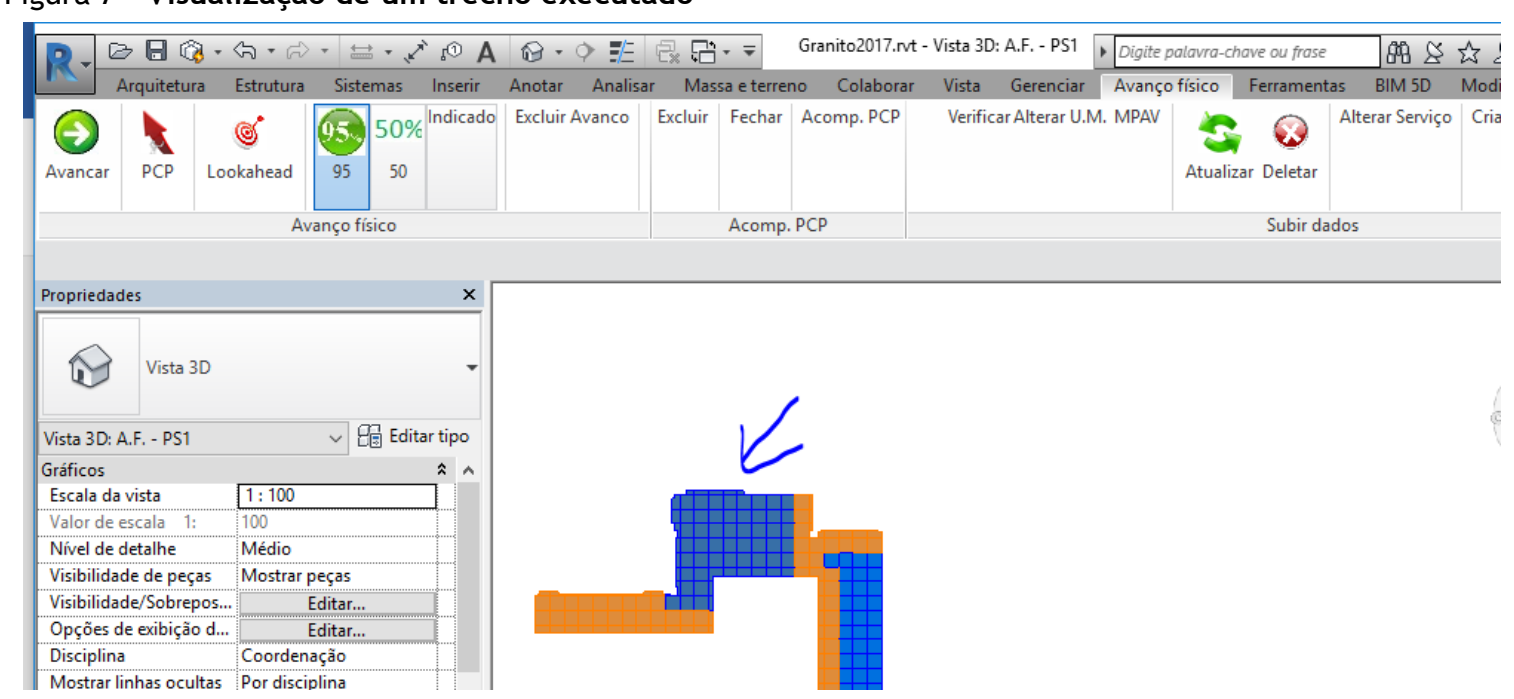


A primeira funcionalidade inserida no software L7 permitiu criar a obra gerenciada e segmentá-la em grupos de serviços, os quais foram decompostos em pacotes de trabalho, de maneira a permitir a formação do lookahead mais detalhado que o plano mestre. Isso possibilita a inserção das informações sobre as composições unitárias dos pacotes de trabalho criados no software L7. Dessa maneira, cada elemento geométrico pode ser associado aos vários insumos necessários a sua execução.

Com o objetivo de acompanhar a evolução da obra, outra funcionalidade desenvolvida no software L7 foi a geração de gráficos comparativos entre o serviço previsto e o realizado. Na Figura 8 é apresentado um exemplo que ilustra o serviço previsto (representado pela linha tracejada) de assentamento de revestimento em granito e o serviço efetivamente realizado (representado pela linha sólida).

Outra funcionalidade destinada ao acompanhamento da obra foi a de associar configurações de equipes (em número de colaboradores) aos consumos de mão de obra obtidos, como se pode observar na Figura 9. Neste exemplo, que ilustra a execução do serviço de assentamento de revestimento em granito, o indicador de eficiência da mão de obra, expresso em números índices, apresenta valores variando próximos a 1,00, independentemente das configurações das equipes.

Outra funcionalidade criada no software L7 foi a relacionada ao gerenciamento dos materiais existentes na obra. Após a criação dessa funcionalidade, todo o material que ingressava no estoque da obra passou a ser registrado no modelo, o que permitiu verificar a disponibilidade desse insumo na análise de restrições no lookahead.

\section{Modelo de integração do BIM ao LPS}

Após o desenvolvimento apresentado nas seções 4.1 a 4.3, o modelo BIM passou a ser suportado pelo acoplamento de um plug-in ao software Revit, com o objetivo de propiciar a ligação dos elementos geométricos à estrututura analítica do projeto (transformando os dados gerados pelo Revit, com extensão .rvt em dados que alimentavam um banco de dados criado no sistema Firebird 3.0, com extensão .fbd, e vice-versa). Outra associação necessária à integração com o planejamento foi a inserção dos dados referentes aos insumos (materiais, mão de oba e especificações de projeto) necessários à realização dos serviços programados, viabilizando o planejamento e o controle da produção de forma visual dentro de um modelo 4D.

Figura 8 - Gráfico destinado ao acompanhamento da obra gerado pelo software L7

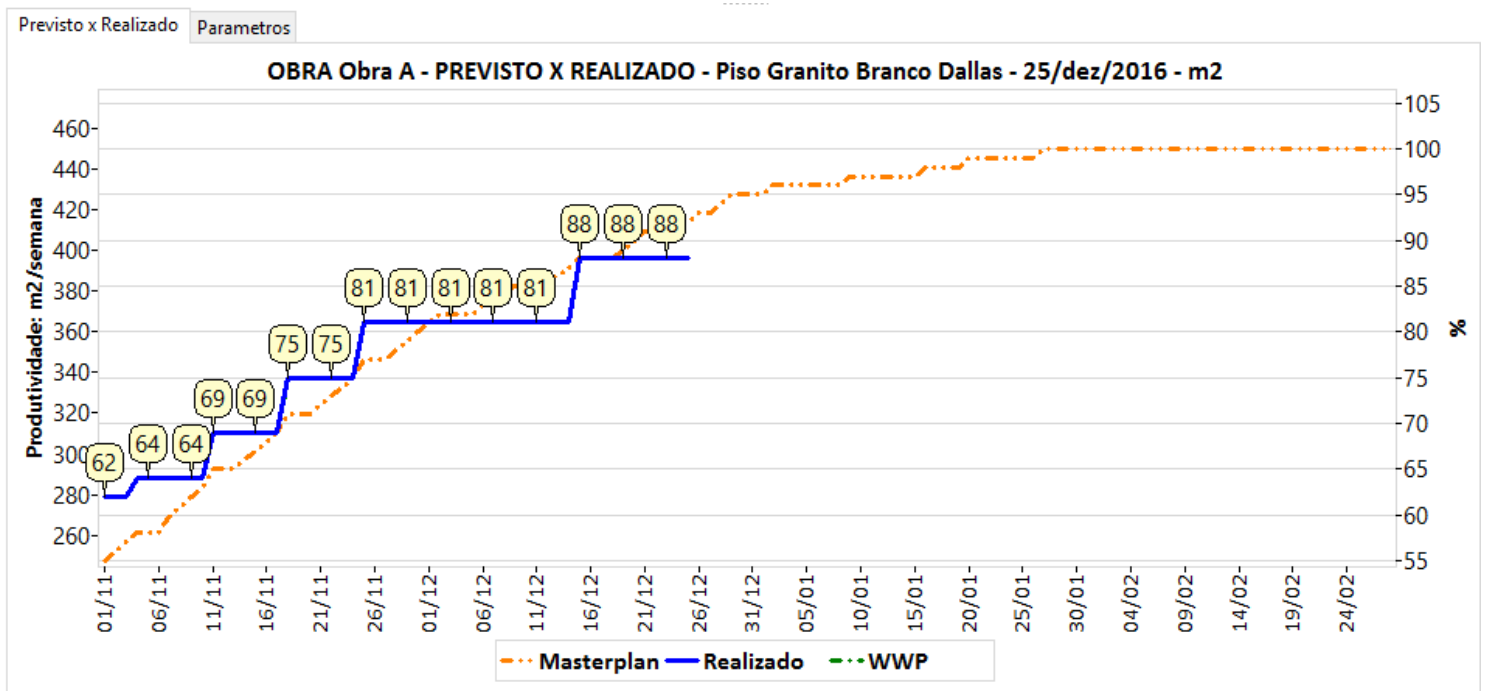

310 Rodrigues, P. B. de F.; Machado, R. L.; Mendes Júnior, R.; Romagnoli, L. D. S. C. 
Figura 9 - Gerenciamento da mão de obra presente na obra

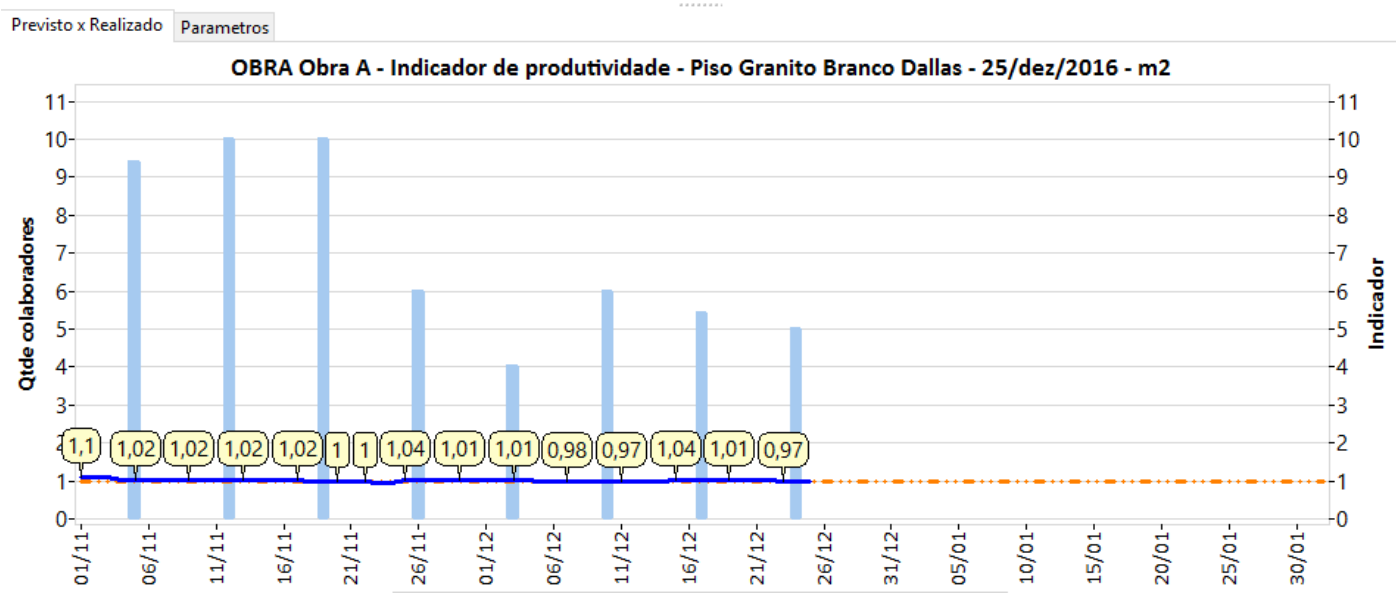

O artefato desenvolvido por esta pesquisa, envolvendo a integração do sistema Last Planner com a modelagem do projeto em $3 \mathrm{D}$, passou a funcionar conforme o modelo apresentado na Figura 10. Como indicado nessa figura, o modelo de integração entre o LPS e o BIM inicia-se com a criação da obra, em que a estrutura analítica detalhada do projeto que permite a formação dos planos de médio e curto prazos é inserida no software L7 e define o plano mestre, para servir como referência de prazo contratual. Ainda nesse momento são definidas as composições unitárias de cada serviço previsto no projeto, no que se refere aos insumos materiais e de mão de obra necessários à sua execução. Essa estrutura, criada no software L7, fica registrada por meio de códigos numéricos gerados no banco de dados Firebird 3.0, no qual será armazenada a informação gerada para a comunicação entre o modelo 3D e o software L7.

O passo seguinte é a preparação do modelo 3D para o planejamento. Faz-se necessária a ligação dos elementos geométricos do modelo 3D à estrutura analítica do projeto e ao consumo dos insumos necessários para execução de cada um dos elementos geométricos. Isso é feito com a criação dos parâmetros de projetos que foram descritos anteriormente. Dessa maneira, há a ligação do modelo 3D com o banco de dados, o que é proporcionado pelo plug-in adicionado ao software Revit, desenvolvido nesta pesquisa.

Por meio do plug-in é possível a transformação dos dados em extensão .rvt, oriundos do software Revit, em dados com extensão .fbd, do banco de dados Firebird, e vice-versa, viabilizando o planejamento.

A partir desse estágio tem-se o modelo pronto para a aplicação da lógica do LPS, que será realizado de forma visual no software Revit. O processo é iniciado com o lookahead, em que, por meio das funcionalidades adicionadas pelo plug-in, é possível selecionar os trechos do projeto que se pretende executar.

Os serviços, agora já detalhados, selecionados para inserção no planejamento, passam por um procedimento de verificação das necessidades de materiais, mão de obra e especificações de projeto, informadas através do software L7, a fim de identificar as restrições existentes para tal plano.

O gerenciamento é feito de forma visual, uma vez que, havendo restrições, o trecho ficará apresentado na cor vermelha, com emissão de um alerta sobre qual restrição deve ser removida. Quando não existe restrição, o trecho é apresentado pela cor verde claro, indicando que as tarefas passam a estar disponíveis para serem incluídas no WWP.

Esse planejamento, após sessão de aprovação de comprometimento com as equipes responsáveis pelos serviços, será selecionado para ser realizado na semana em questão. Os serviços aprovados nesse estágio receberão no acompanhamento visual a cor verde em um tom mais escuro que o definido no lookahead.

Após a execução do serviço é feito o avanço físico, atribuindo a data de execução do trecho em questão. Posteriormente, o trecho executado receberá a cor azul para a gestão visual dentro do próprio software Revit.

Automaticamente, por meio do plug-in desenvolvido, essas informações vão para o banco de dados Firebird 3.0, podendo ser visualizadas no software L7, no qual as várias etapas construtivas controladas em arquivos separados podem ser visualizadas juntas, em forma de gráficos e planilhas, com as datas e agendamentos, bem como a comparação entre o progresso previsto e o realizado. 
Figura 10 - Modelo BIM 4D desenvolvido na pesquisa

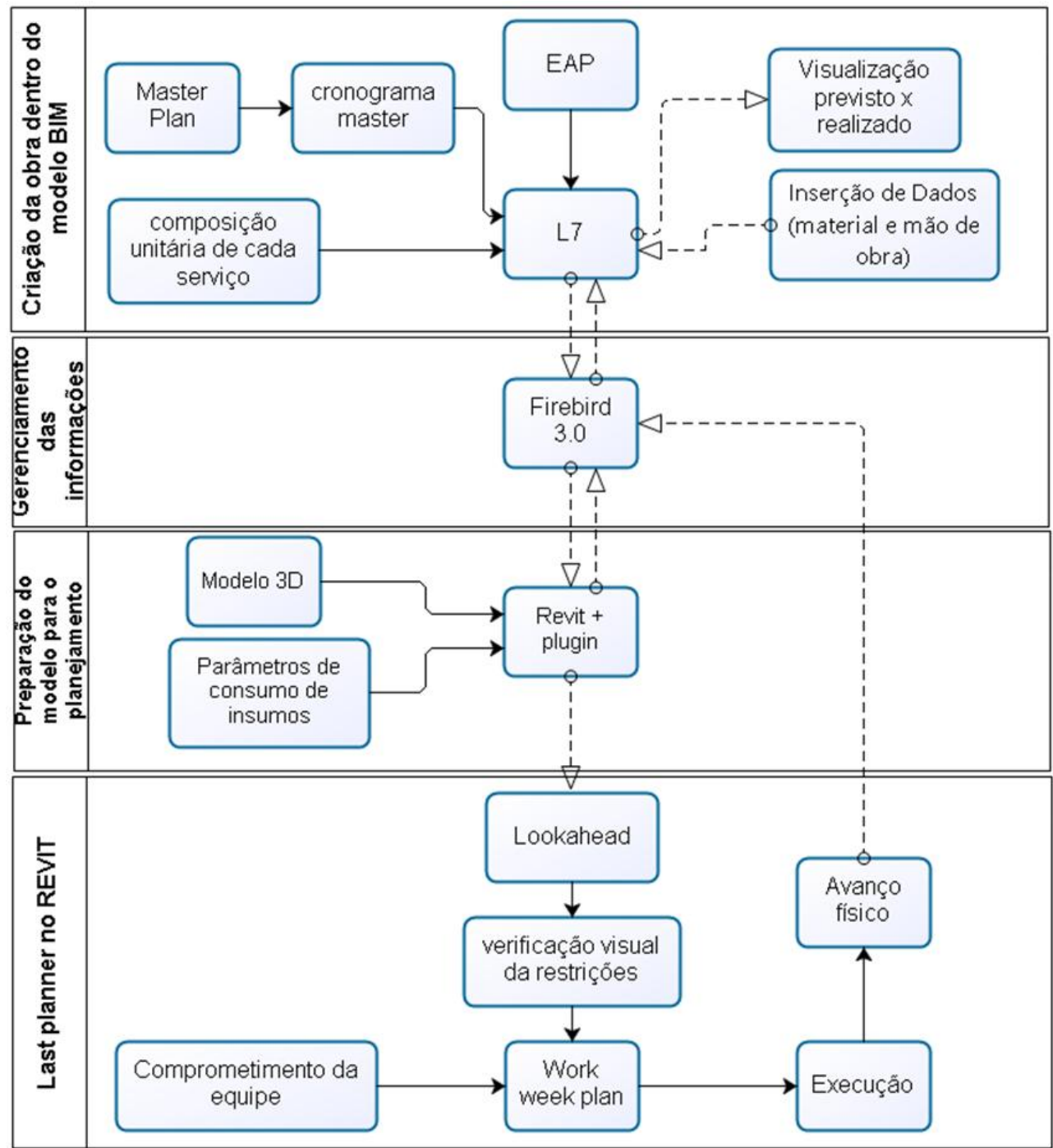

No software L7 é também feita a entrada das informações referentes à mão de obra e aos materiais existentes na obra. Esse controle pode ser feito semanalmente, diariamente, ou quando necessário, permitindo a atualização de informações a respeito dos insumos existentes na obra. Dessa forma, são realizados os ciclos de planejamento até que os serviços sejam totalmente concluídos.

\section{Implantação do modelo proposto}

A implantação do modelo ocorreu em quatro semanas, durante o mês de janeiro de 2017. Essa delimitação temporal coincidiu com o período de conclusão dos serviços acompanhados. Ao longo desse período foram coletados dados de acompanhamento da obra referentes aos serviços realizados, consumo de mão de obra e materiais, a fim de compará-los com os dados gerados pelo modelo, para verificar suas potencialidades $\mathrm{e}$ vulnerabilidades.

Foram estudados os serviços de execução de instalações de incêndio e assentamento de revestimento em granito.

$\mathrm{Na}$ preparação do modelo 3D foram atribuídos pesos aos parâmetros de projeto do software Revit criados para comparar produtividade, controlar o consumo de material e associar os materiais específicos para cada trecho executado.

Após inserir a estrutura analítica do projeto e as composições unitárias de cada serviço no software L7 e definir os parâmetros de projetos utilizados nas definições de quantidades de mão de obra e de materiais requeridos em cada trecho a ser executado, o modelo BIM 3D foi considerado preparado para ser utilizado no modelo de integração proposto nesta pesquisa. 
Houve a necessidade de atualizar o avanço físico para o acompanhamento dos serviços aplicando o modelo proposto. Além disso, foi necessário inserir no software L7 as informações referentes à mão de obra utilizada. Para isso, foi analisado o documento de obra intitulado "Diário informativo", no qual era registrada sistematicamente a atuação dos colaboradores que executaram serviços. As informações a respeito dos materiais foram inseridas de acordo com os pedidos de compra aprovados.

Após o modelo ser alimentado com as informações referentes à mão de obra, aos materiais comprados, ao avanço físico de todos os trechos já executados e à passagem pelo setor de projetos, para indicar trechos que estavam com restrição (devido à falta de detalhamento ou mudança de projeto), o modelo foi considerado pronto para o uso.

Foi realizado, então, o primeiro lookahead, referente ao mês de janeiro de 2017. Em seguida, foi realizado o WWP e o acompanhamento do serviço executado (Figura 11).

Com a aplicação do modelo no serviço de assentamento de granito foi possível identificar que ele trouxe informações importantes sobre a mão de obra, que anteriormente eram registradas em outra planilha, sem conexão alguma com o planejamento. Nesse sentido, os gestores puderam tomar conhecimento de onde estava sendo aplicada a mão de obra do empreiteiro e entender a razão do atraso no serviço, além de identificar o melhor local para atuação da equipe.

Também foi possível observar que as restrições ligadas às especificações de projeto precisavam ser apontadas antes do início do planejamento. Como exemplo, quando a paginação do revestimento em granito foi alterada, caso a mudança tivesse sido comunicada ao responsável pelo planejamento, a previsão de material seria mais precisa e a solicitação antecipada. Nesse sentido, o modelo promoveu a interação das partes interessadas, aumentando a comunicação entre os setores da empresa.
A mudança do planejamento da última semana, alterando os serviços, só foi possível por meio da identificação das causas ocorridas nas semanas anteriores, proporcionando uma melhor gestão e, consequentemente, melhorando a eficiência do planejamento de curto prazo e o tornando formal, com a utilização do modelo.

Com o grupo de serviços da instalação de combate ao incêndio, ficou claro que o modelo poderia antecipar a falta de material e evitar o atraso na execução dos serviços, conforme apresentado na Figura 12.

Também foi constatado que se a execução não seguisse o projeto, o modelo teria pouca utilidade, uma vez que os quantitativos gerados não seriam condizentes com a realidade e, portanto, a verificação das restrições na funcionalidade lookahead também não seriam verdadeiras, no que diz respeito aos materiais, conforme apresentado na Figura 13.

Verifica-se na Figura 13 uma alteração do projeto de instalação de combate a incêndio não prevista no projeto original, modelado no software Revit, o que desencadeou um problema durante a execução do serviço.

A sinalização do departamento de projetos sobre a alteração na locação da casa de bombas também alertou a suspensão da programação do trecho, mostrando a importância desse tipo de restrição, conforme apresentado na Figura 14.

Outro ponto verificado foi a quantidade de trechos apontados como terminados que necessitavam de finalização. Como o modelo possuía a opção de avanço parcial do serviço em valores percentuais, isso poderia ter sido utilizado para sinalizar que era necessária a formação de equipes para essas finalizações e ajustar a programação no sentido de incluir uma nova frente de serviços, ou mesmo não iniciar outros trechos sem a finalização dos anteriores.

\section{Figura 11 - Trechos do lookahead do mês de janeiro referentes ao serviço de assentamento de} revestimento em granito

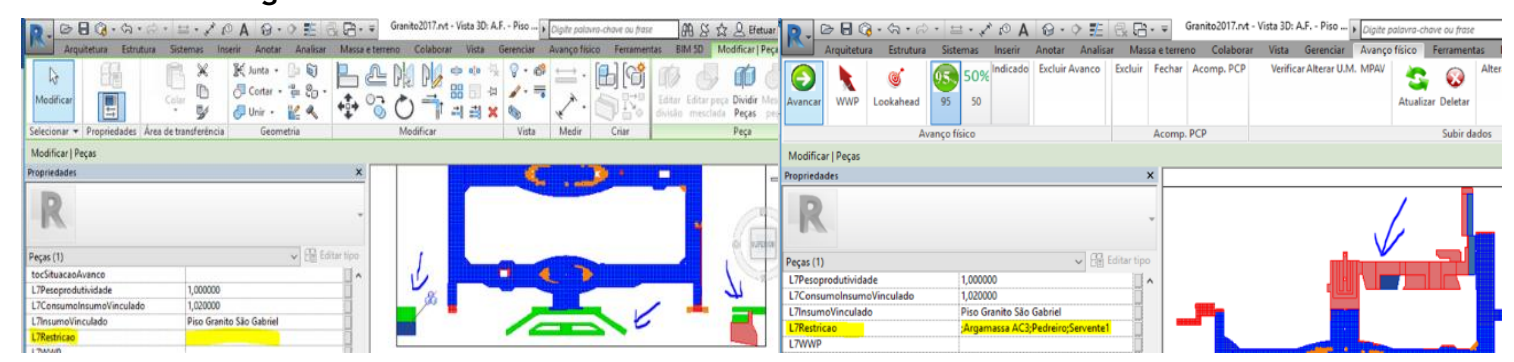


Figura 12 - Trechos do lookahead do mês de janeiro referentes ao serviço de instalação de combate a incêndio

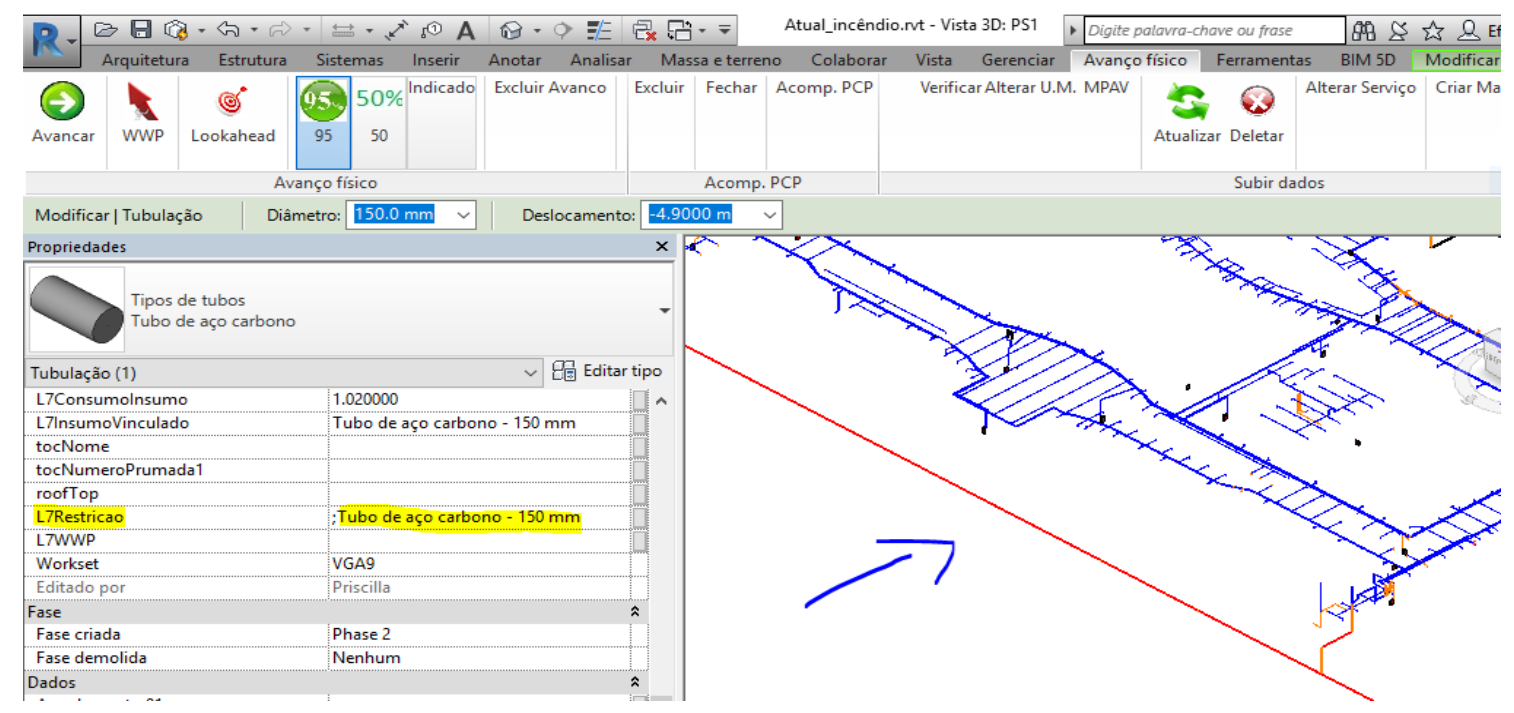

Figura 13 - Trecho executado diferente do previsto em projeto
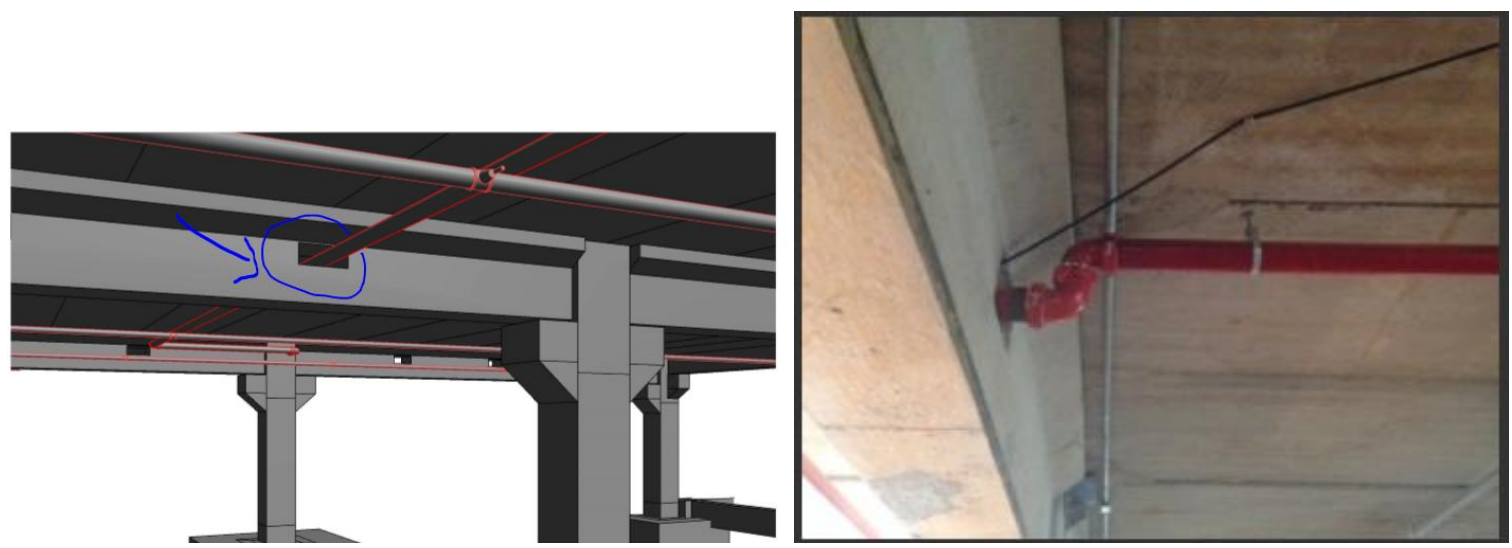

Figura 14 - Trecho com restrição de projeto devido a uma alteração na locação da casa de bombas

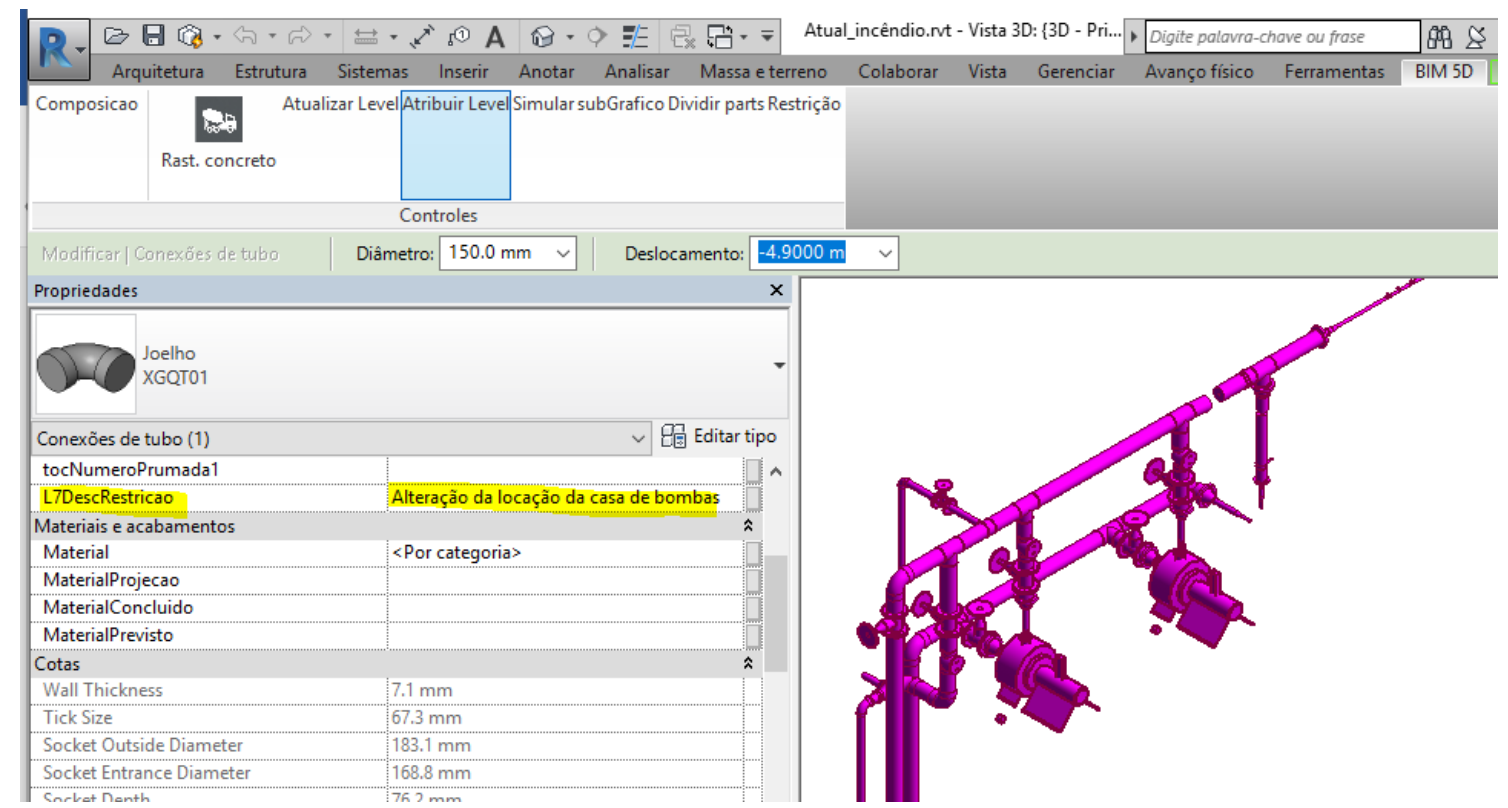

314 Rodrigues, P. B. de F.; Machado, R. L.; Mendes Júnior, R.; Romagnoli, L. D. S. C. 


\section{Avaliação do modelo proposto por seus usuários}

Após a aplicação do modelo no estudo empírico, foi realizada reunião com os colaboradores da obra em que a pesquisa ocorreu, com o objetivo de avaliar sua utilidade e funcionalidade.

\section{Avaliação da utilidade do modelo proposto}

Na avaliação da confiabilidade da informação, constatou-se divergência entre o material solicitado ao departamento de suprimentos e o requerido pelo modelo. Esse problema foi causado por ações na etapa de execução da obra que foram deliberadamente distintas do previsto no projeto.

As informações referentes à mão de obra se mostraram confiáveis, sendo confirmadas pelo setor de produção da obra, que ratificou os dados sobre produtividade e quantidade de colaboradores em cada frente de serviço. Outro elemento que apresentou confiabilidade foi o acompanhamento dos trechos executados, os quais podiam ser identificados no modelo por meio do gerenciamento visual, através das diferentes cores adotadas.

O aumento da comunicação foi o resultado mais útil gerado pelo modelo, conforme a visão dos entrevistados. Isso ocorria quando o departamento de projetos inseria as mudanças de projeto de forma visual diretamente no modelo.

Já sobre a integração das informações em um banco de dados único, verificou-se que os envolvidos no planejamento vislumbraram a possibilidade e utilizá-las para a gestão e execução.

Outro aspecto enfatizado foi a utilidade do gerenciamento visual com cores diferentes para serviços executados, planejados com restrição e sem restrição. A inserção do lookahead também foi notada como um ponto positivo, uma vez que antecipava as restrições, de maneira a eliminá-las antes do início da execução.

A busca automática das necessidades de mão de obra e materiais no modelo, proporcionado pelas funcionalidades do plug-in e do banco de dados, também foi apontada como facilitadora da programação, contribuindo para a melhoria do planejamento, uma vez que tal verificação não era realizada de maneira sistemática.

\section{Avaliação da funcionalidade do modelo proposto}

A facilidade em entender as informações geradas foi reconhecida pela gestão visual, visto que facilitou muito a visualização do serviço programado em relação ao realizado.

Quanto à facilidade de operação da ferramenta, o setor de produção não mostrou interesse em utilizar o modelo. Já o setor de planejamento, que operava o software Revit, teve uma interação bastante satisfatória, não apresentando dificuldade em operá-lo.

As maiores dificuldades encontradas na operação do modelo foram relativas à inserção de dados referentes aos materiais, pois eram frequentes situações em que fornecedores diferentes adotavam nomenclaturas distintas para o mesmo insumo, que, por sua vez, eram diferentes do que estava registrado no elemento geométrico modelado no software Revit. Além disso, também foi constatada uma restrição relativa à coleta de dados de mão de obra para cada serviço, pois a obra registrava apenas o número de colaboradores por grupo de serviços, enquanto no modelo havia a necessidade de se registrar a quantidade de colaboradores por serviço.

\section{Conclusões}

Por meio do modelo proposto as informações necessárias à lógica do LPS foram reunidas em um único banco de dados, promovendo a interação dos departamentos e das partes interessadas e agregando informações que antes ficavam em documentos isolados e por vezes deixavam de ser utilizados na formação do planejamento e controle da produção.

O plug-in desenvolvido acrescentou funcionalidades agregadas ao software Revit, capazes de promover o gerenciamento visual do planejamento lookahead, verificando automaticamente as restrições relativas à mão de obra, materiais e especificações de projetos. Por meio da emissão de alertas visuais com cores diferentes para trechos com tarefas sem restrições e para trechos que possuíam restrições tornou-se possível gerar um banco de tarefas que pudessem ser incluídas no planejamento de curto prazo WWP.

O software desktop foi desenvolvido para gerenciar as informações que necessitavam ser atreladas a cada elemento geométrico do modelo e identificá-las em uma estrutura analítica de projeto, bem como as necessidades específicas de 
insumos referentes a cada serviço do planejamento da produção.

Durante a implantação da proposta foi possível observar a aproximação e a melhoria da comunicação entre os departamentos de planejamento, produção, projetos e suprimentos. $\mathrm{O}$ modelo concentrava as informações necessárias à formação dos planos de médio e curto prazos, que se encontravam isolados nos diversos departamentos e muitas vezes nem eram utilizados para a programação dos serviços.

A identificação das restrições e o gerenciamento visual foram alcançados de maneira satisfatória, mediante a verificação automática realizada pela função lookahead do plug-in instalado. $\mathrm{O}$ gerenciamento visual por meio das cores se mostrou bastante atrativo aos usuários, o que possibilita maior facilidade de interpretação das informações verificadas.

Por fim, a sinergia decorrente da integração do BIM 4D com o LPS, por meio da verificação automática das restrições na elaboração do lookahead, do gerenciamento visual e da integração das partes envolvidas com o planejamento, gerou um sistema de planejamento e controle de médio e curto prazo mais eficientes.

Uma limitação existente no modelo de integração ocorre quando há necessidade de alteração de algum elemento geométrico no modelo $3 \mathrm{D}$, no momento de sua execução. $\mathrm{O}$ modelo de integração ainda não consegue promover automaticamente a inclusão ou exclusão do elemento geométrico em seu banco de dados sua atualização, sendo necessário um procedimento manual. Outra limitação existente no modelo de integração é a ausência de verificação da restrição referente ao serviço antecessor.

Desta pesquisa emergiram questionamentos que são apresentados a seguir como sugestões para trabalhos futuros:

(a) aprimorar o modelo de integração de modo que seja capaz de receber alterações automáticas no modelo 3D; e

(b) elaborar aplicativos para dispositivos móveis (como tablets ou smartphones), que auxiliem na coleta de dados de campo diretamente no modelo.

\section{Referências}

BALLARD, G. Look ahead Planning: the missing link in production control.In: ANNUAL CONFERENCE OF THE INTERNATIONAL GROUP FOR LEAN CONSTRUCTION, Gold Coast, 1997. Proceedings... Gold Coast: IGLC, 1997.
BALLARD, G.; HOWELL, G. Shielding

Production: an essential step in production control. Technical Report n. 97 -1, Construction Engineering and Management Program, Department of Civil and Environmental Engineering, University of California, 1998.

BALLARD, G. The Last Planner System of production control. Ph.D. Dissertation. England: University of Birmingham, 2000.

BERNARDES, M. M. S. Desenvolvimento de Um Modelo de Planejamento e Controle da Produção Para Micro e Pequenas Empresas de Construção. Porto Alegre, 2001. Tese (Doutorado em Engenharia Civil) - Pós-Graduação em Engenharia Civil - Universidade Federal do Rio Grande do Sul, Porto Alegre, 2001.

BHATLA, A.; LEITE, F. Integration Framework of BIM with the Last Planner System. In: ANNUAL CONFERENCE OF THE INTERNATIONAL GROUP FOR LEAN CONSTRUCTION, 12.,San Diego, 2012. San Diego: IGLC, 2012.

BIOTTO, C. N. Método de Gestão da Produção na Construção Civil com Uso da Modelagem BIM 4D. Porto Alegre, 2012. Dissertação (Mestrado em Engenharia Civil) - Escola de Engenharia, Universidade Federal do Rio Grande do Sul, Porto Alegre, 2012.

DRESCH, A.; LACERDA, D. P.; MIGUEL, P. A. G. Uma análise Distintiva Entre o Estudo de Caso, a Pesquisa-Ação e a Design Science Research.

Revista Brasileira de Gestão de Negócios, v. 17, n. 56, p. 1116-1133, 2015.

EASTMAN, C. et al. BIM Handbook: a guide to Building Information Modeling for owners, managers, designers, engineers, and contractors. New Jersey: Jhon Wiley \& Sons, Inc., 2008.

EASTMAN, C.et al.BIM Handbook: a guido to building information modeling for owners, managers, designers, engineers and contractors. $2^{\text {nd }}$.eD.New Jersey: John Wiley \& Sons, Inc., 2011.

LAUFER, A.; TUCKER, R. L. Is construction Project Planning Really Doing Its Job? A critical examination of focus, role and process.

Construction Management and Economics, v. 5, n. 3, p. 243-266. 1987.

MACHADO, R. L. A Sistematização de Antecipações Gerenciais no Planejamento da Produção de Sistemas da Construção Civil. Florianópolis, 2003. Tese (Doutorado em Engenharia civil) - Programa de Pós-Graduação em Engenharia de Produção, Universidade Federal de Santa Catarina, Florianópolis, 2003. 
MARCH, S. T.; STOREY, V. C. Design Science in the Information Systems Discipline: an introduction to the special issue on design science research. MIS Quaterly, v. 32, n. 4, p. 725-730, 2008.

MENDES JUNIOR, R.et al.Integração da Modelagem da Construção (BIM) Com o Planejamento e o Controle da Produção. In: ENCONTRO NACIONAL DE TECNOLOGIA DO AMBIENTE CONSTRUÍDO, 15., Maceió, 2014. Anais... Maceió: ENTAC, 2014.

\section{NATIONAL BUILDING INFORMATION} MODELING STANDARD. Version 1: part 1: overview, principles, and methodologies. 2007.

RODAS, I. A. R. F. Aplicação da Metodologia BIM na Gestão de Edifícios. Porto, 2015.

Dissertação (Mestrado em Engenharia Civil) Faculdade de Engenharia, Universidade do Porto, Porto, 2015.

\section{RODRIGUES, P. B. F. Uma Proposta de} Integração do Modelo BIM ao Sistema Last Planner. Goiás, 2017. Dissertação (Mestrado em Engenharia de Produção) - Programa de PósGraduação em Engenharia de Produção e Sistemas, Pontifícia Universidade Católica de Goiás, Goiás, 2017.
SACKS, R. et al. KanBIMWorkflow

Management System: prototype implementationand field testing. Lean Construction Journal, p. 19-35, may 2013.

SACKS, R.; RADOSAVLJEVIC, M.; BARAK, R. Requirementes For Building Information Modeling Based Lean Production Management Systems FOR construction. Automation in Construction, v. 19. p. 641655, 2010.

SUCCAR, B. Building Information Modeling Framework: a research and delivery foundation for industry stakeholders. Automation in Construction, v. 18, n. 3 p. 357-375. 2009.

VAN AKEN, J. E. Management Research Based on the Paradigm of the Design Science, the Quest For Field-Tested and Grounded Technological Rules. Journal of Management Studies, v. 41, n. 2, p. 219-246, 2004.

\section{Agradecimentos}

Os autores gostariam de agradecer à Fapeg, que apoiou financeiramente a realização deste trabalho.

Priscilla Borges de Freitas Rodrigues

Escola de engenharia | Pontifícia Universidade Católica de Goiás | Rua 235, 76, Setor Leste Universitário | Goiânia - GO - Brasil | CEP 74175-120 | Tel.: (62) 3946-1000 | E-mail: prisbf@hotmail.com

Ricardo Luiz Machado

Escola de engenharia | Pontifícia Universidade Católica de Goiás | E-mail: drrmachado@gmail.com

Ricardo Mendes Júnior

Departamento de Construção Civil | Universidade Federal do Paraná | Setor de Tecnologia, Centro Politécnico, Bloco III, Jardim das Américas | Curitiba - PR - Brasil | |CEP 81531-980 | Tel.: (41) 3360-5000 | E-mail: mendesjr@ufpr.br

Larsson Diogo Seabra Coelho Romagnoli

Escola de engenharia | Pontifícia Universidade Católica de Goiás | E-mail: larsson.maxeng@gmail.com

Revista Ambiente Construído

Associação Nacional de Tecnologia do Ambiente Construído

Av. Osvaldo Aranha, $99-3^{\circ}$ andar, Centro

Porto Alegre - RS - Brasil CEP $90035-190$

Telefone: +55 (51) 3308-4084

Fax: +55 (51) 3308-4054

www.seer.ufrgs.br/ambienteconstruido

E-mail: ambienteconstruido@ufrgs.br 